\title{
Considerações sobre o Compendium musicae de Descartes: matemática, música e a produção de afetos
}

\section{Considerations on Descartes Compendium musicae: mathematics, music and the production of affections}

\author{
CÉSAR AUGUSTO BATTISTI
}

\begin{abstract}
Resumo: A atual exposição pretende tecer algumas considerações sobre o Compendium Musicae, obra escrita por Descartes, ainda muito jovem, no final do ano de 1618, há 400 anos. O objetivo é apresentar alguns elementos da obra e compará-la com aqueles presentes na Geometria, com o intuito de mostrar paralelos estruturais e semelhanças de natureza epistemológica e metodológica entre elas, bem como evidenciar determinadas características categoriais utilizadas pelo filósofo com vista à produção da inteligibilidade (isto é, da racionalidade) dos fenômenos ou problemas estudados. Como segundo propósito, pretende-se examinar o percurso efetivado por Descartes com vista à compreensão do fenômeno musical, de sua estrutura e de seus elementos componentes, começando pela natureza física do som, passando pela estrutura matemática da música (suas propriedades principais, o tempo e a altura, as relações de maior ou menor consonância entre as notas), até se constituir em um fenômeno relativo à nossa sensibilidade e capaz de fazer emergir em nossa alma afetos e paixões variadas. Como afirma Descartes, o objeto da música é o som, e seu fim é a produção do prazer e a emergência de afetos no ser humano. Circunscrita à sensibilidade humana, a música deixa de ser entendida dentro de uma perspectiva cosmológica e ligada à harmonia das esferas celestes, passando a se configurar como fenômeno relativo à subjetividade humana, ou melhor, ao seu composto alma-corpo.
\end{abstract}

Palavras-chave: Descartes. Compendium Musicae. Música. Matemática. Afetos. Prazer.

Abstract: The present exhibition intends to make some considerations on the Compendium Musicae, written by Descartes, still very young, at the end of the year of 1618, 400 years ago. The objective is to present some elements of the work and compare it with those present in Geometry, in order to show structural parallels and similarities of epistemological and methodological nature between them. All this, besides evidencing certain categorical characteristics used by the philosopher with a view to the production of the intelligibility (that is, of the rationality) of the phenomena or problems studied. As a second purpose, we intend to examine the course carried out by Descartes with a view to understanding the musical phenomenon, its structure and its component elements. This begins with the physical nature of sound, passing through the mathematical structure of music (its main properties, time and height, relations of greater or lesser consonance between notes), until it becomes a phenomenon related to our sensitivity and capable of to bring about in our soul different affections and passions. As Descartes says, the object of music is sound, and its end is the production of pleasure and the emergence of affections in the human being. Circumscribed to the human sensibility, the music is no longer understood within a cosmological perspective and linked to the harmony of the celestial spheres, starting to be configured as a phenomenon relative to human subjectivity, or rather to its soul-body compound.

Keywords: Descartes. Compendium Musicae. Music. Mathematics. Affections. Pleasure.

\footnotetext{
${ }^{1}$ Professor dos Cursos de Graduação e Pós-Graduação (Stricto sensu) em Filosofia da UNIOESTE. Email: cesar.battisti@hotmail.com.
} 


\section{Introdução}

Minha exposição pretende tecer algumas considerações sobre o Compendium Musicae (Compêndio de Música), obra escrita por Descartes nos últimos dois meses do ano de 1618, portanto, há exatos 400 anos. ${ }^{2} \mathrm{O}$ objetivo é aproximar o texto do Compêndio com o da Geometria (ocasionalmente também com o de outras obras), publicada em 1637 ao lado do Discurso do Método e dos demais ensaios do método, a Dióptrica e os Meteoros, com o intuito de mostrar certos paralelos que podem nos conduzir a determinadas semelhanças de natureza metodológica, de natureza estrutural e, de um modo geral, a determinadas características em relação às categorias que o filósofo emprega para produzir a inteligibilidade, se quiserem, a racionalidade, dos fenômenos ou problemas estudados. Na verdade, muitas dessas marcas partilhadas por estes textos se encontram em outros momentos do pensamento cartesiano.

Evidentemente, há uma diferença no estatuto da inteligibilidade subjacente às duas obras. Como afirma F. De Buzon em sua introdução à tradução francesa do Compêndio, a noção de inteligibilidade dessa obra é uma "inteligibilidade não intelectual", uma inteligibilidade oriunda do âmbito "de um sensível tão articulado que se manifesta em proporção sem que o espírito necessite fazer algum esforço de compreensão" (DESCARTES, 1987, p. 12), de modo que, apesar de sua natureza sensível e mesmo pondo certos obstáculos - pelo menos aos guardiões de parâmetros rígidos do racionalismo cartesiano -, ela guarda semelhanças estruturais com a inteligibilidade matemática e, em geral, com a do âmbito do claro e distinto. ${ }^{3}$

\section{O fenômeno}

A primeira marca do Compêndio de Música diz respeito à necessidade de Descartes nos proporcionar, com precisão, a localização teórico-conceitual do fenômeno musical. Essa é uma marca metodológica do pensamento cartesiano: localizar o fenômeno precisamente de modo que isso permita apreender seus ingredientes e dispensar o que é supérfluo. Podemos aproximar essa perspectiva ao que afirma a Regra 13 das Regras para a Direcção do Espírito. Afirma o cabeçalho desta regra:

Se compreendermos perfeitamente uma questão, devemos abstraí-la de todo o conceito supérfluo, reduzi-la à maior simplicidade e

\footnotetext{
${ }^{2}$ Uma primeira versão desta pesquisa foi apresentada, em outubro de 2018, na XXI Semana de Filosofia da UFU, promovida pelo Instituto de Filosofia dessa universidade.

${ }^{3}$ Para informações sobre o Compendium, sobre sua estrutura e sobre a história do texto, cf. as partes introdutórias elaboradas por De Buzon à sua tradução (DESCARTES, 1987).
} 
dividi-la em partes tão pequenas quanto possível, enumerando-as (DESCARTES, 1985, p. 83). ${ }^{4}$

Nesse sentido, podemos ver, já desde o início do Compêndio, que a música e seu objeto, o som, se constituem em um fenômeno cuja complexidade nos revela uma estrutura composta por três níveis de análise ou por três tipos de ingredientes. Podemos classificar a estrutura do fenômeno musical como contendo um componente quantitativo, um componente qualitativo e um outro expressivo.

Em outras palavras, o fenômeno musical é, para Descartes:

(1) um evento acústico (físico-matemático) que

(2) incide sobre nossa sensibilidade, de modo a

(3) incitar na alma a emergência de paixões (fenômeno estético).

Uma vez indicada a composição do fenômeno musical, há ainda um passo fundamental para a sua determinação. Esse passo diz respeito à materialidade do fenômeno, na medida em que ele é um fenômeno acústico e, como tal, relativo à física. Essa materialidade, entretanto, precisa ser ainda mais bem analisada e melhor descomplexificada. Descartes afirma que deixará de fora a investigação sobre as qualidades do som, sua materialidade propriamente dita, cabendo aos físicos fazê-la, incidindo suas investigações sobre a dimensão quantitativa da música; assim, a música é um fenômeno físico-matemático, mas o que interessa é apenas o aspecto matemático. Não é a materialidade do som que atingirá a alma, mas são, de algum modo, as relações matemáticas que provocarão nela o surgimento de emoções. A música propriamente dita não é nem física nem fisiologia: é um fenômeno, embora Descartes não afirme claramente, é um fenômeno da união alma x corpo.

Aqui, mais uma vez, podemos aproximar esse passo metodológico ao que afirmam as Regras, em sua Regra 8, quando Descartes trata da anaclástica, um problema de natureza ótica.

Assim, suponhamos que alguém procura, entregando-se exclusivamente às Matemáticas, essa linha que em Dióptrica se chama anaclástica, ou seja, aquela em que os raios paralelos se refratam de tal forma que todos, depois da refração, têm um só ponto de intersecção. Facilmente observará, sem dúvida, segundo as regras quinta e sexta, que a determinação desta linha depende da relação que os ângulos de refração mantêm com os ângulos de incidência; mas, como não será capaz de procurar minuciosamente esta relação, que diz respeito não à Matemática mas à Física, será forçado a deter-se aqui no limiar. De nada lhe servirá querer aprender este conhecimento dos Filósofos ou extraí-lo da experiência, pois pecaria contra a regra terceira. [...]. Se, por outro

\footnotetext{
${ }^{4}$ Poder-se-ia, por sua vez, aproximar essa Regra com os quatro preceitos metodológicos da Segunda Parte do Discurso do Método.
} 
lado, alguém que não se dedique só às Matemáticas, mas que, segundo a primeira regra, deseje procurar a verdade em tudo quanto se lhe depare, cair na mesma dificuldade, descobrirá, além disso, que a relação entre os ângulos de incidência e os ângulos de refração depende da sua mudança devido à diversidade dos meios; que, por seu turno, esta mudança depende da maneira como o raio penetra através de todo o corpo diáfano, e que o conhecimento desta penetração supõe o conhecimento da natureza da ação da luz; e que, por fim, para compreender a ação da luz, é preciso saber o que é em geral uma potência natural: é, em última análise, o que há de mais absoluto em toda esta série (DESCARTES, 1985, p. 46-47).

Neste exemplo da anaclástica, diz Descartes, caberá ao físico, e não ao matemático, investigá-la, ao passo que, no caso do fenômeno da música, caberá ao matemático, e não ao físico, fazê-lo, mas a atitude epistêmica do investigador, em relação à determinação da natureza do fenômeno em questão, é semelhante.

Assim, do fenômeno musical, enquanto fenômeno físico, são suas relações matemáticas que importam. E parece dizer Descartes que são tais relações que devem ter um correspondente estético na alma. As propriedades materiais do som, por outro lado, não interessam; Descartes deixa essa questão sob a responsabilidade dos "Physiciens" (DESCARTES, 1987, p. 54). Em razão disso, Descartes não trata do timbre, dada a sua natureza qualitativa, restringindo-se às duas afeções suscetíveis de um tratamento matemático, a duração (ou ritmo) e a altura (ou a diferença entre grave e agudo).

Para finalizar o processo de determinação precisa do fenômeno musical, é necessário assinalar ainda duas coisas. A determinação da estrutura do fenômeno musical pressupõe a sua desvinculação de dois outros horizontes, os quais historicamente fizeram parte do estudo do fenômeno.

O primeiro deles é a desvinculação do fenômeno musical de questões místicas e relacionadas à estrutura do cosmos, como as que dizem respeito à música das esferas celestes. O segundo diz respeito à não-necessidade de uma discussão histórica do fenômeno: embora Descartes não desconheça as pesquisas já feitas, elas devem ser introduzidas, caso necessário, no interior da investigação do fenômeno propriamente dito. É o fenômeno em sua articulação interna que clama por elementos que, porventura, já foram investigados por este ou aquele autor.

A primeira marca da investigação cartesiana é a delimitação teórico-conceitual do fenômeno, e, com isso, a delimitação da realidade mesma do fenômeno. Soma-se a isso que todo elemento a ser introduzido na investigação deve ser uma exigência interna das relações existentes no fenômeno estudado. É a dinâmica interna que comanda a investigação e determina seus elementos componentes. É o próprio fenômeno a ser investigado, no âmbito de sua estrutura interna, que estabelece ou determina suas exigências, as quais se encontram nele mesmo, isto é, se encontram 
imersas na complexidade mesma que o constitui, de sorte que estamos a priori assegurados de que tudo o que é preciso, todos os elementos necessários à sua inteligibilidade estão aí presentes e devem se deixar manipular e compreender por nossas capacidades cognitivas.

O correspondente matemático da noção de fenômeno é a noção de problema. Assim, à localização investigativa de um fenômeno corresponde, por sua vez, a determinação do lugar e da natureza de um problema investigado. A Geometria se organiza ao redor dos problemas geométricos concebidos por Descartes (na verdade, uma retomada da classificação grega, por meio do texto de Pappus) e de sua divisão em problema planos, sólidos e mais que sólidos. A Geometria se circunscreve ao redor da resolução dos problemas geométricos, e sua estrutura é determinada em razão disso, de modo que Descartes abre seu texto falando de todos os problemas e finaliza sua obra retomando a classificação dos problemas e afirmando ter resolvido a todos eles.

Na Geometria, é igualmente a lógica interna dos problemas e de sua dinâmica resolutiva que comandam e determina o que Descartes faz, como faz e seu direcionamento. Um problema bem determinado contém tudo o que precisa para ser resolvido: neste caso, trata-se de descobrir as relações resolutivas fundamentais. É por isso que o procedimento analítico dos geômetras gregos pode pressupor o problema resolvido e reconhecer que tudo o que a sua resolução exige encontra-se potencialmente presente em sua própria estrutura.

Assim, o plano geral da Geometria consiste na classificação dos problemas em três tipos, hierarquizados e sucessivos, cada qual exigindo um conjunto de procedimentos resolutivos. Se o livro 1 da Geometria trata dos problemas planos e o livro 3 dos problemas sólidos e mais que sólidos, o livro 2 precisou tratar dos meios (das curvas geométricas) que, dispensáveis na resolução dos planos, são necessários aos problemas posteriores, mais complexos.

De um modo geral, o processo investigativo para Descartes tem como ponto de partida seja o fenômeno a ser estudado seja o problema a ser resolvido, ambos claramente circunscritos e determinados. A estrutura de um fenômeno, como o musical, tem uma estrutura análogo à de um problema matemático ou a de um problema ótico como o da anaclástica. Essa é uma marca do pensamento cartesiano, e ela já aparece em seu primeiro escrito, o Compêndio de Música.

\section{Dinâmica geral}

Uma vez circunscrita a região do fenômeno a ser estudado, Descartes procede à investigação dos elementos que o compõem. No caso do fenômeno musical, essa investigação se guiará pelos três elementos indicados acima: a sua componente 
estético-expressiva, a sua dimensão sensível e a sua estrutura de natureza quantitativa.

Além disso, há uma direção privilegiada nessa análise. Como quem analisa algo, Descartes parte do que é mais evidente e imediatamente dado e vai em direção aos pressupostos do fenômeno. Em outras palavras, há um movimento regressivo do fato de que a música nos proporciona o prazer para a busca, por assim dizer, das suas condições de possibilidade de produção do prazer. Descartes faz um movimento regressivo que vai do que nos é dado imediatamente pelos sentidos e pela nossa natureza composta, lugar de produção das paixões, em direção às capacidades do objeto, do som, responsáveis por produzir ou por colocarem em movimento o que há de específico na música. Se é o som, vindo do exterior, que nos proporciona as afecções, o prazer e as paixões, é destas que parte a análise, retroativamente, para chegarmos às propriedades matemáticas do som, subentendidas nessa dinâmica que compõe o fenômeno musical.

Nesse sentido, o ponto de partida (a) da investigação cartesiana do fenômeno musical é o seu fim: o de produzir prazer e o de provocar em nós a emergência de paixões variadas. Diz o texto de abertura do Compêndio: tratando-se da música, cujo objeto é o som, "seu fim é o de agradar e o de provocar em nós paixões [afetos] variadas”. E, em seguida, diz a primeira Observação Preliminar do texto: "Todos os sentidos são capazes de algum prazer" (DESCARTES, 1987, p. 54). ${ }^{5}$

Ora, só há música, se houver produções de paixões em alguém, em nós. Dado que essa é a sua finalidade, o que é requerido para que ela se concretize? A música é proveniente de uma relação entre som e emergência de paixões, sendo o som (vindo de fora) e as paixões (internas) os seus dois extremos: tudo o que vier a ser analisado se encontra entre esses dois extremos.

O procedimento cartesiano, embora partindo do fim, se pauta pela observação dos extremos e pelo preenchimento dos elementos intermediários necessários à ocorrência do fenômeno. Assim, embora partindo do fim, Descartes mantém sob os olhos o começo, e busca preencher os espaços intermediários necessários à construção da inteligibilidade do fenômeno musical.

O segundo passo (b) da análise cartesiana é a indicação da necessidade da existência de um elemento que possibilite a passagem do objeto físico até nossa capacidade receptiva desse objeto, ou seja, a necessidade da existência, como afirma a segunda Observação Preliminar, de "uma certa proporção do objeto com o sentido mesmo" (DESCARTES, 1987, p. 56) que o capta. Se os sentidos são apropriados à emergência de paixões, eles exigem relações de proporcionalidade, isto é, de comensurabilidade, entre o som e a capacidade que o capta, o ouvido.

\footnotetext{
${ }^{5}$ A obra, depois de tratar rapidamente de seu objeto, apresenta oito Observações Preliminares, cuja importância é fundamental (cf. DESCARTES, 1987, p. 54-59).
} 
Os sentidos procedem à passagem do quantitativo para o qualitativo. Para isso, é preciso introduzir um intermediário, algo como um quantitativo sensível. A proporcionalidade captada pelos sentidos, embora se paute numa proporcionalidade matemática, não é rigorosamente matemática: ela é uma transposição da inteligibilidade matemática para uma inteligibilidade sensível. Embora seja difícil determinar com precisão essa passagem, certo é que os sentidos captam ou aceitam certas relações de proporcionalidade, assimilando-as. Alguns critérios são dados por Descartes.

Mas, antes de fornecer tais critérios, talvez vale a pena aproximar esse percurso de passagem do quantitativo matemático para o quantitativo sensível com uma passagem do livro 6 da Dióptrica, em que Descartes fala de uma "geometria natural" (Descartes, 2018, p. 169; AT VI, p.137) como forma de explicar a percepção unificada de um objeto e a sua distância, tendo em conta a estrutura geométrica da luz e dos raios envolvido em um fenômeno da visão e sua entrada por cada um dos nossos olhos. Assim, há uma geometria natural que permite a percepção de relações quantitativas e de unificação dos diferentes meios percebidos. Talvez possamos dizer algo análogo do ouvido, dos dois ouvidos: haveria certas relações de proporcionalidade na música perceptíveis por eles.

Vamos aos critérios dados por Descartes, principalmente nas Observações Preliminares:

1. O objeto não deve ser excessivamente difícil nem excessivamente confuso. Há uma clareza e distinção própria à sensibilidade correspondente à clareza e distinção captadas pela luz natural da razão.

2. Objetos mais simples, regulares, constituídos de proporções mais simples agradam mais à vista, a satisfazem mais plenamente, dado que seus elementos são percebidos mais facilmente. Assim acontece com o ouvido: percebe-se mais facilmente um objeto na medida em que a diferença entre suas partes seja menor, isto é, na medida em que a proporção seja maior. Quanto maior a proporcionalidade, maior será a semelhança entre os objetos comparados, cujo limite é a igualdade.

3. Nossa sensibilidade, portanto, é capaz de captar, até certos limites, relações de proporcionalidade.

4. Tais relações são mais ou menos agradáveis, em razão de o sentido se satisfazer mais ou menos em função da percepção distinta do objeto. A percepção mais distinta está ligada à proporção matemática maior. Assim, na produção das notas musicais, uma oitava é mais agradável e mais fácil de ser captada do que uma quinta, e uma quinta de uma quarta, dado que a proporção de uma oitava com a nota base (o uníssono) é maior e mais simples (é de 1:2) do que a da quinta, e a proporção da quinta é maior e mais simples do que a da quarta. 
5. A proporção mais fácil e, portanto, a mais adequada para a determinação das notas é a proporção aritmética, por ser mais simples e por se pautar na divisão em partes iguais. A proporção aritmética se compõe a partir de uma medida comum, a unidade, que se repete de uma nota para outra. Ora, diz Descartes, por meio da proporção aritmética os sentidos não se fadigam e não se saturam excessivamente, de modo que possam ter uma percepção suficientemente distinta da relação de uma nota musical com uma outra.

6. Enfim, os objetos dos sentidos que são mais agradáveis à alma não são aqueles mais facilmente ou mais dificilmente percebidos, mas aqueles que estabelecem uma equação entre a facilidade perceptiva em relação ao desejo natural que os sentidos têm para com o objeto, sem que isso provoque a fadiga dos sentidos ou a sua plena saturação.

Estes são os principais critérios que permitem a transposição de construções matemáticas para o âmbito da sensibilidade e, a partir daí, a emergência das paixões relativas ao fenômeno musical.

Dentre os elementos análogos utilizados no Compêndio e na Geometria podemos destacar os seguintes:

i) Primeiramente, o uso da noção de proporção. A teoria das proporções é fundamental na Geometria. Aliada ao uso da noção de unidade (e, portanto, a de medida), elas são responsáveis por uma espécie de revolução na ciência geométrica: elas permitem, nada mais nada menos, do que unificar aritmética e geometria e sanar o problema da incomensurabilidade de operações geométricas. Havia dois principais obstáculos relativos à assimilação entre operações aritméticas e operações geométricas: 1o.) a mudança de dimensão dos objetos resultantes das operações geométricas e sua limitação à tridimensionalidade do espaço, não havendo sentido geométrico para expressões acima do cubo; 2) a diferença de natureza entre magnitudes contínuas (geométricas) e descontínuas (aritméticas). Tais obstáculos foram resolvidos por Descartes por combinação da introdução da unidade (proveniente da aritmética) com o uso da teoria das proporções (utilizada na geometria).

ii) A noção de unidade joga um papel fundamental na Geometria e no Compêndio. Assim, afirma Descartes no Compêndio, o uníssono não é uma consonante, mas "se reporta às consonantes como a unidade aos números" (DESCARTES, 1987, p. 64). O uníssono é a unidade, e as notas consonantes se originam dele por divisão conforme a proporção aritmética, por meio da "aplicação" da unidade. O uso da proporção e da noção de unidade, eis o ponto de partida análogo entre as duas obras.

iii) Disso se origina um terceiro elemento comum entre elas. Tudo o que vem depois, a partir da unidade e da proporção, se dá por um processo de composição 
regrado. A unidade na Geometria é uma reta assumida como tal, e todos os problemas geométricos, afirma Descartes, na abertura do Livro 1, não necessitam, para serem resolvidos, senão do conhecimento do tamanho de algumas retas. Mesmo as curvas geométricas mais complexas são oriundas da composição de retas por meio de movimentos regrados redutíveis a um único. Por sua vez, as curvas mecânicas, ininteligíveis, são compostas por um movimento retilíneo e outro circular, irreconciliáveis, o que faz com elas não podem ser aceitas. Esse movimento de composição está analogamente presente no Compêndio. As consonantes musicais se determinam por composição ou divisão do uníssono, cada vez mais complexas, e os ritmos mais complexos são redutíveis aos ritmos secundário e ternário, simples, visto que todos são ou pares ou divisíveis por três.

iv) Assim, há um critério subjacente a todos esses procedimentos, o critério da simplicidade. Na verdade, são dois critérios na Geometria: o do requisito mínimo e o da suficiência. No Livro 3 dessa obra, Descartes retoma uma passagem de Pappus em que este autor se refere a um erro ou pecado cometido pelos matemáticos, quando resolvem problemas com meios mais complexos que os que são necessários. Descartes, ao contrário de Pappus, fala de dois erros. São erros resolutivos tanto o emprego de meios excessivamente complexos quanto o emprego de meios excessivamente simples. Para evitar o primeiro erro, exige-se que a solução do problema seja a mais simples possível, e a mais simples é aquela que faz uso da curva mais simples, isto é, da curva cuja equação possui o gênero mais baixo dentre todas as que correspondem às soluções possíveis. Para evitar o segundo erro, exigese que se respeitem os requisitos mínimos impostos pelo problema, sendo esse grau mínimo intransponível. E, assim, erra-se seja por excesso resolutivo seja por insuficiência resolutiva, cabendo à entidade "problema" determinar as condições pelas quais eles são evitados. Esse requisito permite a Descartes, no caso do Compêndio, determinar que o tempo ou duração são suficientes para haver música, como é o caso dos instrumentos de percussão, mas que em geral o fenômeno musical supõe tempo e altura. Tempo em alguns casos, tempo e altura nos demais são as propriedades do som que preenchem o que é requerido, como mínimo e suficiente, para a produção do fenômeno musical.

v) Algo semelhante acontece no âmbito da altura das notas musicais. No primeiro nível, há as consonantes. E, dentro deste, há o uníssono e as consonantes mais próximas (como a oitava e a quinta) e, depois, as mais distantes, contendo, por vezes, já algum elemento de dissonância. Em seguida, vêm os intervalos das dissonantes propriamente ditas.

Assim, aqui também, há a unidade ou a medida comum e, em seguida, os critérios de composição, de modo que há uma hierarquia dos intervalos musicais dos mais simples aos mais complexos até o limite das dissonâncias que não são mais 
toleráveis pelo ouvido. Os objetos musicais se organizam de forma análoga aos objetos matemáticos, as curvas geométricas e as equações algébricas.

\section{Conclusão}

Como já dito mais acima, a inteligibilidade do fenômeno musical não é da mesma natureza que a inteligibilidade das questões matemáticas. Na música, há uma inteligibilidade não intelectual, uma inteligibilidade sensível.

Apesar da diferença de estatuto da natureza dessas inteligibilidades, há uma série de expedientes análogos entre as duas obras, o Compêndio e a Geometria, e o objetivo foi analisar um pouco esta estrutura de compreensão entre elas, algo que poderia ser levado adiante para as outras partes dos textos.

Outros elementos da obra poderiam ser examinados sob essa perspectiva, mas os aqui realizados são suficientes para, talvez, fornecer a razão de a tradução francesa do Compendium Musicae ter sido publicado por N. Poisson, em 1668, ao lado da Dióptrica e dos Meteoros, como se fosse um ensaio do método (cf. DESCARTES, 1987, p. 41).

\section{Referências}

DE BUZON, F. Science de la nature et théorie musicale chez Isaac Beeckman (1588-1637). Revue d'histoire des sciences, 38, 2, 1985, p. 97-120.

DE BUZON, F. Sympathie et antipathie dans le Compendium Musicae. Archives de Philosophie, 46, 1983, p. 647-653.

DESCARTES, R. A geometria. In: Discurso do Método E Ensaios. Tradução e notas de César Augusto Battisti. São Paulo: Ed. Unesp, 2018.

DESCARTES, R. Abregé de musique. Tradução, apresentação e notas de Frédéric de Buzon. Paris: PUF, 1987.

DESCARTES, R. Compendium musicae. In: CEuvres de Descartes. Edição de Charles Adam e Paul Tannery. Paris, Vrin, 1996. Vol. X.

DESCARTES, R. Discours de la méthode E Essais. In: CEuvres de Descartes. Edição de Charles Adam e Paul Tannery. Paris, Vrin, 1996. Vol. VI.

DESCARTES, R. Regras para a direcção do espírito. Tradução de João Gama. Porto: Ed. 7o, 1985.

KRANTZ, É. Essai sur l'esthétique de Descartes. Paris: Librairie Félix Alcan, 1898.

PEREIRA, A. Teoria musical e estética no Compendium Musicae de Descartes. Revista Portuguesa de Musicologia, 6, 1996, p. 99-107.

VAN WYMEERSCH, B. Descartes et l'évolution de l'esthétique musicale. Sprimont (Bélgica): Bardaga, 1999.

VAN WYMEERSCH, B. L'esthétique musicale de Descartes et le cartésianisme. Revue Philosophique de Louvain, 4/94, 2, 1996, p. 271-293. 
Considerações sobre o Compendium musicae de Descartes: matemática, música e a produção de afetos

Submissão: 10.05.2018 / Aceite: 29.11.2018.

34 